\title{
Interplay between inflammatory tumor microenvironment and cancer stem cells (Review)
}

\author{
SHIJIAN ZHANG ${ }^{1,2^{*}}$, XI YANG $^{1,2^{*}}$, LEI WANG ${ }^{1,2}$ and CHENPING ZHANG ${ }^{1,2}$ \\ ${ }^{1}$ Department of Oral and Maxillofacial-Head and Neck Oncology, Ninth People's Hospital, \\ Shanghai Jiao Tong University School of Medicine; ${ }^{2}$ Shanghai Key Laboratory of Stomatology and \\ Shanghai Research Institute of Stomatology, National Clinical Research Center of Stomatology, Shanghai 200011, P.R. China
}

Received May 29, 2017; Accepted May 10, 2018

DOI: $10.3892 / \mathrm{ol} .2018 .8716$

\begin{abstract}
Cancer stem cells (CSCs), which have a close connection with tumor microenvironment, play a pivotal role in tumorigenesis, tumor progression, and metastasis. The inflammatory microenvironment is an essential component of tumor microenvironment. In the recent years, many studies have demonstrated that the inflammatory microenvironment induces the initiation of tumors, and contributes to the process of the progression of tumors, as well as metastasis. In this review, we summarize the relationship between CSCs and inflammatory components, such as inflammatory cytokines (IFNs, TNF, IL-6, IL-17) and inflammatory cells (myeloid-derived suppressor cells, tumor-associated macrophages). To illuminate the key factors that exert important actions in the tumor process would be important to improve the clinical outcome of the treatment for different types of cancer.
\end{abstract}

\section{Contents}

1. Introduction

2. Inflammatory cytokines

3. Inflammatory cells

4. Conclusion

Correspondence to: Professor Chenping Zhang or Dr Lei Wang, Department of Oral and Maxillofacial-Head and Neck Oncology, Ninth People's Hospital, Shanghai Jiao Tong University School of Medicine, 639 Zhizaoju Road, Shanghai 200011, P.R. China

E-mail: zhang.chenping@hotmail.com

E-mail: wanglei@sh9hospital.org

${ }^{*}$ Contributed equally

Key words: tumor microenvironment, inflammatory factors, cancer stem cells, interferons, tumor necrosis factor, myeloid-derived suppressor cells, tumor-associated macrophages

\section{Introduction}

Cancer stem cells (CSCs), which was first reported by Dick and his colleagues in acute myeloid leukemia (AML) (1), have been identified in many solid tumors. It is extensively accepted the importance of CSCs in tumorigenesis, tumor progression, metastasis and relapse. CSCs are capable of preserving cancer heterogeneity through reserving self-renewal and differentiation abilities. In addition, CSCs activate the resistance mechanisms, including downregulation of replication, expression of drug export systems, epithelial-to-mesenchymal transition (EMT) and enhanced resistance to hypoxia with induction of angiogenesis and immune escape by reducing tumor specific antigens, while increasing anti-inflammatory cytokines and growth factors (2). The positioning of stem cells in normal organs has been identified, and it has been suggested that the interaction of microenvironment with stem cells is pivotal for the maintenance of stemness (3). CSCs may localize at specific niche like stem cells in normal organs (4). Due to the significance of tumor microenvironment, it is a reasonable strategy to regulate the stem cell niche to inhibit CSC survival. Among the multiple causes of malignant tumor, infection has been considered as a major navigator of inflammation-induced tumorigenesis (5). It has been accepted that the inflammatory microenvironment is an essential component of CSCs niche. Cancer can be promoted by inflammation, via enhancing proliferative and survival signaling, induction of invasion and metastasis. In this review, we summarize the major molecular and cellular mechanisms that participate in the reciprocal action between CSCs and inflammatory mediators (Figs. 1 and 2; Table I). The emerging mechanisms of inflammatory factors-induced stemness of CSCs are outlined. A better understanding of the role of the crosstalk between CSCs and inflammatory microenvironment might prospectively lead to more efficient therapies against cancer initiation and progression.

\section{Inflammatory cytokines}

Interferons (IFNs). IFNs are a group of pleiotropic cytokines that participate in multiple biological activities, such as antivirus infection, regulation of cell proliferation and immunological response (6). They are classically divided among three species: 
Type I IFNs; Type II IFNs; and Type III IFNs, and the two main categories in mammals are Type I and II. Type I contains two primary members, IFN- $\alpha$ and IFN- $\beta$, and the IFN- $\gamma$ is the lonely member of the type II (7). Indeed, IFNs have been verified in the therapies of several types of cancer with success, such as chronic myeloid leukemia, T and B cell lymphomas, melanoma, renal carcinoma and so on. However, under certain conditions, IFNs was found to augment the numbers of T regulatory cells (Tregs) and Th17 cells. The myeloid-derived suppressor cells (MDSCs) that induced by IFNs, can express as protumorigenesis factors and promote the tumor cells escape from immunosurveillance (8). Therefore, IFNs participate in tumor immunology as a 'double-edged sword'.

Mesenchymal stem cells (MSCs) are multipotential stromal cells that can differentiate into kinds of cell types, such as osteoblasts, chondrocytes, myocytes and adipocytes (9), and with self-renewal and pluripotent differentiation abilities, possessing the potential to displace damaged and diseased tissues (10). There is a closely interaction between the MSCs and the host immune system, the ability to inhibit proinflammatory cytokines of MSCs sets up the foundation for clinical applications in treating autoimmune diseases (11). In recent years, the MSCs have been proved to accelerate cancer progression in several types of cancer, and the IFNs have been shown to play critical roles in it. Wang et al demonstrated that IFN- $\gamma$ and TNF- $\alpha$, as two important representative inflammatory factors, play a crucial role in synergistically inducing MSCs deficiency and eventual MSCs tumorigenesis via the $\mathrm{NF} \kappa \mathrm{B}$ pathway in OVX-induced osteoporotic mice (12). Their research indicated that IFN- $\gamma$ and TNF- $\alpha$ contributes in the MSCs-based tissue regeneration (13). It is also reported that IFN- $\gamma$ and TNF- $\alpha$ in the MSCs enhanced tumor cells malignancy, induced EMT of breast cancer cells, and papillary thyroid cancer cells $(14,15)$.

Numerous studies have demonstrated that IFNs are closely related to the CSCs, in the tumor cells proliferation, therapy resistance, and metastasis. Schürch, et al gived evidences of that IFN- $\gamma$ induce proliferation and differentiation of chronic myeloid leukemia stem cells (16). In pancreatic carcinoma cells, IFN- $\alpha$ up-regulates the expression of CSC markers, promotes the metastasis formation (17). Yamashina et al revealed that the cancer stem-like cells from chemo-resistant tumors are able to produce IFN-regulated transcription factors, which promote macrophage colony-stimulating factor (M-CSF) production and generate tumorigenic myeloid cells, then facilitate the tumorigenic and stem cell activities of bulk tumors (18). In glioma stem cells, it is also demonstrated that the IFN-regulated factors promote tumorigenicity, angiogenesis, microglia recruitment and maintain glioma stem cells properties through induction of interleukin $6, \mathrm{C}-\mathrm{X}-\mathrm{C}$ motif chemokine 1 and $\mathrm{C}-\mathrm{C}$ motif chemokine 2 (19). Ojha R and his colleagues reported that in bladder cancer cells, JAK-mediated autophagy regulates stemness and cell survival via IFN- $\gamma(20)$. In hepatocellular carcinoma, the researchers demonstrated that the IFN- $\gamma$ treatment enriched the $\mathrm{CD}_{133^{+}}$liver CSCs population in vitro and in vivo (21).

In addition to the above, the IFNs could promote tumor progression via downregulating tumor antigens, facilitating angiogenesis, and maintaining an immunosuppressive tumor microenvironment $(22,23)$. The roles of IFNs in malignancies maybe determined by tumor microenvironment, tumor types, and tumor stage and so on, for the two faces of IFNs in cancer, further studies are in great request to provide a promising prospect for IFNs-based treatment.

Tumor necrosis factor (TNF). TNF superfamily refers to a group of cytokines that can cause cell death, the two main members of the family are TNF- $\alpha$ and TNF- $\beta$. Given that TNF- $\alpha$ accounts for 70 95\% of TNF biological activities, it can represent the TNF superfamily in general (24). By virtue of the ability to cause cytolysis of certain tumor cell lines, TNF- $\alpha$ has been utilized as a potential anticancer agent for many years (25), but with the development of research, emerging evidences suggest that TNF- $\alpha$ is significant in promoting tumor progression, in particular, with CSCs.

TNF- $\alpha$ can induce EMT and increase stemness properties, that is demonstrated in renal cell carcinoma, hypopharyngeal cancer and cholangiocarcinoma cells $(26,27)$. Synergized with IFN- $\gamma$, TNF- $\alpha$ stimulates MSCs to enhance malignancy of cancer cells, tumorigenesis (12-14), and resistance to chemotherapy (28). Yu et al validated that TNF- $\alpha$-activated MSCs promote breast cancer metastasis via recruiting CXCR2 ${ }^{+}$ neutrophils (29), a similar result is reported by Katanov C and his colleague (30).

In recent studies, it is revealed that TNF- $\alpha$ enhances CSCs phenotype of oral squamous cell carcinoma (OSCC) cells, such as an increase in tumor sphere-formation ability, stem cell associated genes expression, chemo-radioresistance, and tumorigenesis (31). Besides that, TNF- $\alpha$ upregulates SLUG (a mediator of EMT process) with a dependency on canonical NFkB/HIF1 $\alpha$ signaling, then imparts breast cancer cells with stem cell-like features (32). In melanoma, it is evidenced that after treatment of TNF- $\alpha$, the self-renewing capacity of stem-like cells is upregulated (33). The transcription factor Atonal homolog 1 (Atoh1) protein, stabilized by TNF- $\alpha$, could enrich colon CSCs, and induce high malignant potential (34). In myeloid leukemia, TNF- $\alpha$ secreted by the CSCs could promote NFKB pathway/p65 pathway and support stem cells survival $(35,36)$. Similarly, TNF- $\alpha$ induces NFkB pathway activation to protect colorectal CSCs from death, and induce tumor regression (37).

For the importance of TNF- $\alpha$ in promoting tumorigenesis and progression, it represents a novel target in tumor prevention and therapy (28). However, more studies are needed before ideal clinical outcomes can be achieved (38).

IL-6. IL-6 is one member of the ILs, which acts as both a pro-inflammatory cytokine and an anti-inflammatory myokine (39). IL-6, also referred to as B-cell stimulatory factor-2 (BSF-2) and IFN $\beta-2$, is a cytokine that regulates the immune response but also plays a role in modulating cell growth, differentiation, and survival. It is mainly secreted by $\mathrm{T}$ cells, macrophages and fibroblasts. IL- 6 belongs to the 'IL-6 type cytokine' family that also includes leukemia inhibitory factor (LIF), IL-11, ciliary neurotrophic factor (CNTF), cardiotrophin-1 (CT-1) and oncostatin M (OSM) (40). IL-6 mediates its activity by a cell-surface typeIcytokine receptor complex, which includes the ligand-binding IL-6R $\alpha$ chain (IL-6R, CD126), and the signal-transducing component gp130 (CD130) (41). After interaction with its receptor, IL-6 triggers 


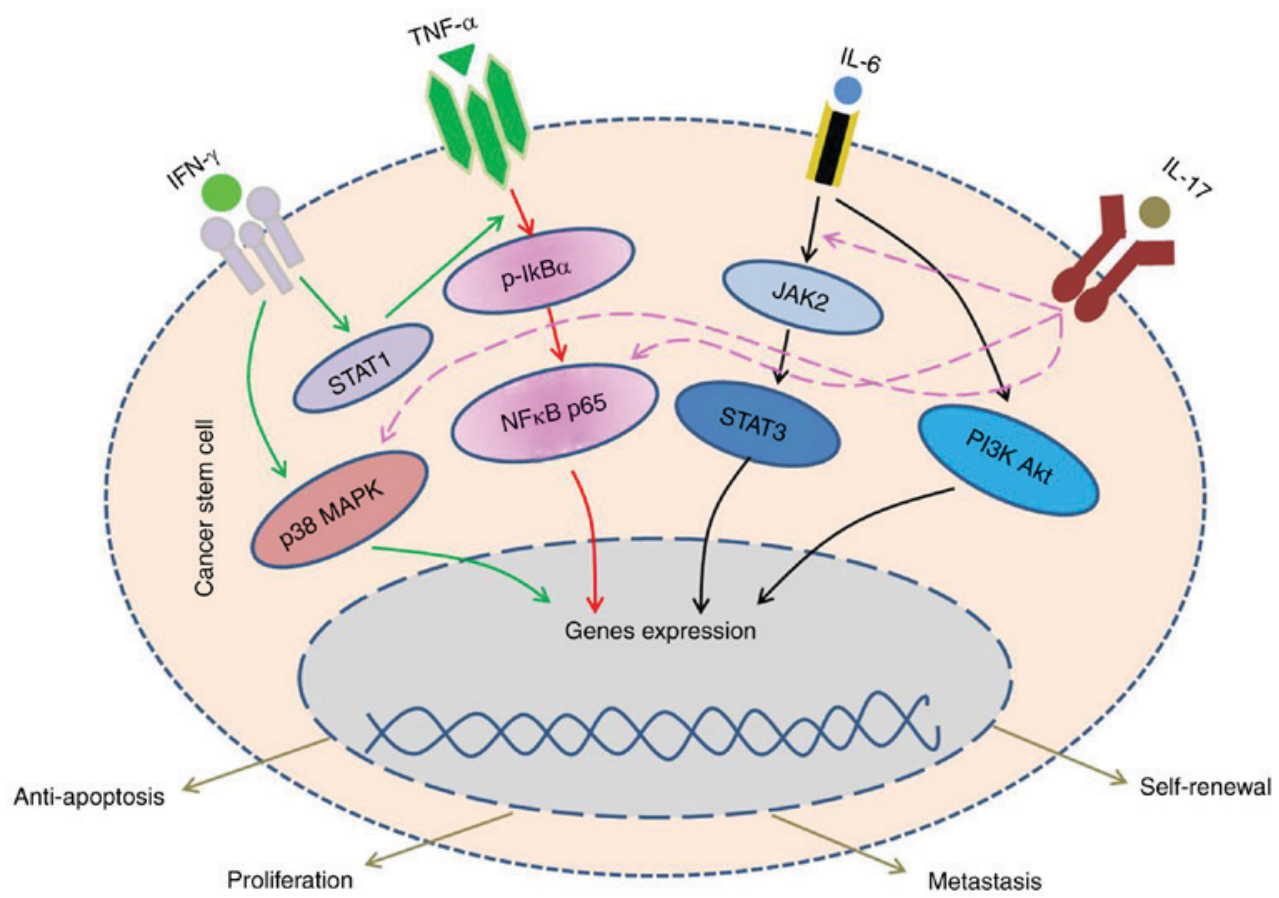

Figure 1. IFN- $\gamma$, by binding to the IFNAR on CSCs, lead to the activation of NFKB, p38/MAPK and STAT pathways. After integrated with the TNFR, TNF- $\alpha$ increases the stemness property and enhance the proliferation of CSCs. IL-6 acts on the IL-6 receptor expressed by CSCs and activates JAK/STAT, PI3K/Akt pathways, then to facilitate the self-renewal of stem-like cells and enhance their tumorigenic potential. The JAK/STAT, NFKB and p38/MAPK pathways also could be activated by IL-17 and IL-17R. CSCs, cancer stem cells; IFN, interferon; JAK, Janus kinase; STAT, signal transducer and activator of transcription; p38, tumor protein 38; MAPK, mitogen-activated protein kinase; Akt, protein kinase B; TNF, tumor necrosis factor; TNFR, TNF receptor; NFkB; nuclear factor $\mathrm{kB}$; JNK, c-Jun N-terminal kinases; PI3K, phosphatidylinositol 3-kinase; IL, interleukin.

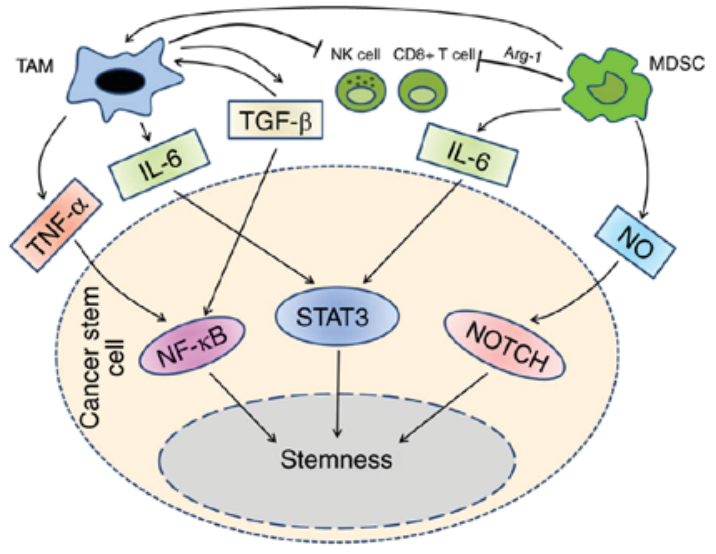

Figure 2. MDSC population could differentiate into TAMs, in tumor microenvironment, they suppress NK cells, $\mathrm{CD} 8^{+}$cells and other immune cells synergistically. The cytokines exist in tumor microenvironment mediate the interaction between TAMs and MDSCs with CSCs. TAMs activates NFKB and STAT3 pathways through TNF- $\alpha$, IL- 6 and TGF- $\beta$. In addition to IL-6, MDSCs utilize NO to activate STAT3 and NOTCH pathways. By means of these signal pathways, TAMs and MDSCs drive CSCs development, enhance the invasion and migration. CSCs, cancer stem cells; STAT, signal transducer and activator of transcription; TNF, tumor necrosis factor; NFkB; nuclear factor $\kappa \mathrm{B}$; IL, interleukin; MDSCs, myeloid-derived suppressor cells; TAMs, tumor-associated macrophages; TGF, transforming growth factor.

the IL-6R and gp130 proteins to form a complex, which stimulates distinct pathways to perform its oncogenic consequence, these pathways consist of Janus kinases (JAK)/signal transducer and activator of transcription (STAT), mitogen-activated protein kinase (MAPK) and phosphatidylinositol 3 kinase (PI3K)/protein kinase B (Akt) (42).
The varying biological functions of IL-6 make it critical in the enhancement or suppression of tumor growth and progress, and it is involved in the proliferation and differentiation of malignant cells and found to be high in serum and tumor tissues of a majority of cancers, including prostate cancer (43), multiple myeloma (44), renal cell carcinoma (45) and breast cancer (46). Emerging evidences suggest that the IL-6 levels in the serum are implicated in aggressive tumor growth and response to therapies in many types of cancer, and also could be a prognostic marker for assessing disease stage and disease progression (43).

To be valid in the protumorigenesis, IL-6 frequently interacts with CSCs, such as moderating CSCs differentiation and maintaining the stemness of cancer cells. In lung cancer cells, IL-6 promotes the self-renewal of $\mathrm{CD} 133^{+} \mathrm{CSC}$-like cells, and the IL-6 expressing CD133+ cells have significantly higher expression of EMT-related molecules (lower E-cadherin, higher $\mathrm{N}$-cadherin, vimentin, and TWIST), as well as higher expression of metastasis-related molecules [MMP9, transforming growth factor (TGF)- $\beta 1$ ] than IL-6 knocked down CD133+ cells (47). In subsequent study, it is reported that IL-6 signaling induces DNA repair while preventing $\mathrm{CD} 133^{+} \mathrm{CSC}$-like cells from apoptotic death after radiation for lung cancer (44). Likewise, in cisplatin-resistant lung cancer cells, IL-6 plays an important role in triggering enhanced stemness during cisplatin resistance development, through the upregulation of hypoxia-inducible factors (HIFs) (48). Liu et al (49) reported the IL-6/JAK2/STAT3 pathway upregulates DNA methyltransferase 1 (DNMT1) and promotes cancer initiation and lung CSCs proliferation by downregulation of $\mathrm{p} 53$ and $\mathrm{p} 21$ resulting from DNA hypermethylation. By the activation of IL-6/JAK2/STAT3 pathway, 
Table I. A list of some CSC-related inflammatory cytokines, ligands, origins and their functions.

\begin{tabular}{|c|c|c|c|c|c|}
\hline Item & Origin & Receptors & Signal pathway & Functions (in tumor) & (Refs.) \\
\hline IFN & $\begin{array}{l}\text { Host cells } \\
\text { (virus-infected cells) } \\
\text { Fibroblasts } \\
\text { Macrophages } \\
\text { T helper cells }\end{array}$ & $\begin{array}{l}\text { IFNGR1,2 } \\
\text { IFNAR1,2 } \\
\text { IFNLR1 }\end{array}$ & $\begin{array}{l}\text { JAK/STAT } \\
\text { p38/MAPK } \\
\text { PI3K/Akt } \\
\text { C3G/Rap1 }\end{array}$ & $\begin{array}{l}\text { Induce EMT } \\
\text { Downregulate tumor-antigens } \\
\text { Facilitate angiogenesis } \\
\text { Promote CSCs proliferation }\end{array}$ & $1,2,7-21$ \\
\hline $\mathrm{TNF}$ & $\begin{array}{l}\text { Activated-macrophages } \\
\text { CD4 }{ }^{+} \text {lymphocytes } \\
\text { NK cells } \\
\text { Neutrophils } \\
\text { Mast cells }\end{array}$ & $\begin{array}{l}\text { TNFR1 } \\
\text { TNFR2 }\end{array}$ & $\begin{array}{l}\text { NFкB/HIF1a } \\
\text { JNK/MAPK }\end{array}$ & $\begin{array}{l}\text { Induce EMT } \\
\text { Increase stemness property } \\
\text { Support CSCs survival } \\
\text { Enhance proliferation }\end{array}$ & $7-9,22-27,31-37$ \\
\hline IL-6 & $\begin{array}{l}\text { Macrophages } \\
\text { Th2 cells } \\
\text { B cells } \\
\text { Astrocytes } \\
\text { Endothelium }\end{array}$ & $\begin{array}{l}\text { CD126/IL6RA } \\
\text { CD130/IR6RB }\end{array}$ & $\begin{array}{l}\text { JAK/STAT } \\
\text { PI3K/Akt }\end{array}$ & $\begin{array}{l}\text { Downregulate E-cadherin } \\
\text { Moderate CSCs' differentiation } \\
\text { Protect CSCs from apoptosis } \\
\text { Alter DNA methylation }\end{array}$ & $39-42,43,44,47-50$ \\
\hline IL-17 & Th17 & $\begin{array}{l}\text { IL-17RA, B, } \\
\text { C, D and E }\end{array}$ & $\begin{array}{l}\text { p38/MAPK } \\
\text { AP-1 } \\
\text { JAK/STAT3 } \\
\text { NFאB }\end{array}$ & $\begin{array}{l}\text { Drive CSCs' development } \\
\text { Promote CSCs' self-renewal } \\
\text { Enhance stemness, invasion, } \\
\text { and migration }\end{array}$ & $57-59,61-66$ \\
\hline
\end{tabular}

CSC, cancer stem cells; IFN, interferon; IFNAR, IFN- $\alpha / \beta$ receptor; JAK, Janus kinase; STAT, signal transducer and activator of transcription; p38, tumor protein 38; MAPK, mitogen-activated protein kinase; Akt, RAC- $\alpha$ serine/threonine protein kinase; C3G, Rap1, Ras-related protein 1; TNF, tumor necrosis factor; TNFR, TNF receptor; NFкB; nuclear factor $\kappa \mathrm{B}$; HIF1a, hypoxic inducible factor $1 \alpha$; JNK, c-Jun N-terminal kinases; PI3K, phosphatidylinositol 3-kinase; AP-1, activator protein 1; EMT, epithelial-to-mesenchymal transition; Th, T helper cells; NK cells, Natural killer cells; CD, cluster of differentiation; IL, interleukin; IL6RA, IL 6 receptor.

MSCs can enhance the capability of tumor initiation in lung cancer cells (50). Correspondingly, TME and/or tumor cells can impact the function of IL-6. Lu et al (51) revealed that the adipose-derived stem cells (ADSCs) enhance the malignant characteristics of Lewis lung carcinoma cells, including cell growth ability and especially CSC property. Glioma stem cells (GSCs) initiate microglial IL-6 secretion via TLR4 signaling and that IL-6 induces glioma growth by supporting GSCs, and glioma-associated microglia/brain macrophages are the primary source of IL-6 in tumor (52). By secreting high levels of IL-6, ovarian MSCs (OvMSCs) enhance the proliferation, sphere and colony formation and tumorigenesis of SKOV3 cells (53). In colorectal cancer (CRC), it is proposed that CD90 ${ }^{+}$ fibroblasts/myofibroblasts may be the major source of IL-6 in T2-T3 CRC tumors, then supports the stemness of tumor cells and mediates the immune adaptive inflammatory response favoring tumor growth (54). The role of epigenetic control in cancer onset and development has been extensively accepted in recent years, e.g., the IL-6/JAK2/STAT3 pathway upregulates DNA methyltransferase 1 (54), the long non-coding RNAs (lncRNAs) in liver CSCs (LCSCs) mediate the crosstalk between TNF- $\alpha / N F \kappa B$ signaling and autocrine IL-6/STAT3 cascade, then suppressed LCSCs expansion by inhibiting IL-6 transcription and STAT3 activation (55). In monoclonal gammopathy of undetermined significance (MGUS) and multiple myeloma, the IL-6 production in the bone marrow MSC (BMMSC) is driven by the citrullination of histone $\mathrm{H} 3$ (56).
Overall, these evidences suggest that IL-6 is involved in mechanisms of CSCs stemness, and the significance of IL-6 in the crosstalk between tumor and its microenvironment. Therefore, the inhibition of IL-6 may be a useful adjunct to cancer therapy, with a need of targeting this protein to combat cancer.

IL-17. IL-17 is a potent proinflammatory cytokine mainly produced by activated T-helper 17 cells (Th17) and activated by IL-23. The IL-17, also called IL-17A, is the fundamental member of a group of cytokines called IL-17 family. Besides of IL-17A, there are IL-17B, IL-17C, IL-17D, IL-17E (also called IL-25), and IL-17F constitute this family. The IL-17 receptor group includes five receptors, IL-17RA, B, C, D and E (57). IL-17 binds IL-17R, and then forms a complex to mediate a variety of signaling pathway, such as JNK, Erk1/2, p38, AP-1, JAK/STAT3 and NFKB (58). By virtue of these pathways, IL-17 induces the production of many other cytokines (such as IL-6, G-CSF, GM-CSF, IL-1 $\beta$, TGF- $\beta$, and TNF- $\alpha$ ), chemokines (IL-8, GRO- $\alpha$, and MCP-1), and prostaglandins (e.g., PGE2) from many cell types, then to play an important part in the initiation and progression of many diseases. As a pivotal factor of tumor microenvironment, IL-17 could facilitate cancer progression, from tumorigenesis, migration, invasion, and metastasis, to adapting the tumor in its ability to confer upon itself both immune evasion, and chemotherapy resistance (59).

In view of the significance of CSCs in the cancer progression, the interplay between IL-17 and CSCs has aroused great 
interests of the scientists and researchers in recent years. In CRC, the sphere cells cocultured with Foxp $3^{+} \mathrm{IL}-17^{+}$cells could express more CRC cell markers (CD133, CD44s, CD166, EpCAM, and ALDH1) than the control sphere cells, and when neutralizing anti-IL-17 antibody was added to the culture, the expression of CD133 and the rest of the CRC cell markers was abolished. These data suggest that Foxp $3^{+} \mathrm{IL}-17^{+}$cells are capable of driving cancer-initiating cells (CICs) development (60). In this study, they also demonstrated that hypoxia induces Foxp3+Tregs to express IL-17. Consistently, it is revealed that Th17 stemness may be partially controlled by signaling pathways such as hypoxia inducible factor HIF1 $\alpha$, Notch and $\mathrm{Bcl}$ (61). Lotti et al (62) reported that IL-17A can contribute to CICs maintenance through IL-17A receptor in CRC, and then promote protumorigenic CICs behavior, as well as contribute to $\mathrm{CIC}$ therapeutic resistance. It is also demonstrated that one role of IL-17 in ovarian CD133 ${ }^{+}$cancer stem-like cells (CSLCs) is to promote the self-renewal (63). By IL-17 overexpression, the growth and sphere formation capacities of ovarian CD133 ${ }^{+}$ CSLCs were dramaticlly enhanced. The incentive function of IL-17 might be mediated by the NFאB and p38/MAPK signaling pathway. In human hepatocellular carcinoma (HCC), IL-17E binding to IL-17RB motivates NFKB and JAK/STAT3 pathways to facilitate propagation and self-renewal ability of CSCs, and these beneficial effects could be prevented by specific inhibitors of JAK and NFאB signals (64). Similarly, by NFאB and STAT3 pathways, IL-17-IL-17R interaction in glioma stem cells (GSCs) induces an autocrine and/or paracrine cytokine feedback loop, that may provide an important signaling pathway for the stemness of GSCs (65). In addition to that, the upregulation of IL-17 in gastric cancer results in the transformation of quiescent gastric CSCs into invasive gastric CSCs, from invasion, migration to tumor formation ability (66).

For the significance of the interaction between IL-17 and CSCs, targeting IL-17 may emerge as a feasible novel therapeutic strategy. That clearly demonstrates a need for more research in this area, and the potential application of anti-IL-17 in the overall management will be hopeful.

\section{Inflammatory cells}

MDSCs. MDSCs are one of the major cell populations in charge of mediating immune responses, and are a heterogeneous population of cells comprised of macrophages, dendritic cells (DCs) and granulocytes, which expand during tumor progression, autoimmune disease, infection and other pathological conditions, and can efficiently suppress $\mathrm{T}$ cell function (67). The immune cells of MDSCs are from the myeloid lineage (a family of cells that originate from bone marrow stem cells) and are consist of myeloid-cell progenitors and precursors of myeloid cells. Under normal condition, the immature myeloid cells (IMCs) quickly differentiate into mature granulocytes, macrophages or DCs, but in abnormal conditions such as cancer, infectious diseases, trauma or some autoimmune disorders, IMCs differentiate into MDSCs (68). A number of immune suppressive factors are associated with the immunosuppressive function of MDSCs, including arginase (encoded by ARG1), inducible nitric oxide synthase (iNOS, or $\mathrm{NOS}_{2}$ ), nitric oxide (NO) and reactive oxygen species (ROS). The signaling pathways activated in MDSCs induced biological process are mainly STAT6, STAT1, and NFKB.

In addition to the immunological functions, non-immunological functions of MDSC also should been illustrated, such as the promotion of tumorigenesis, tumor invasion and metastasis (69). Given that CSCs are responsible for cancer initiating, progression, metastasis and recurrence, it is reasonable to hypothesize that there are mutual effects between CSCs and MDSCs, and then mounting evidences verify the existence of the relationship. In an early study, the CD $44^{+}$cancer stem-like cells are shown to not only more strongly inhibit T-cell proliferation, but also more efficiently induce regulatory $\mathrm{T}$ cells (Treg cells) and MDSCs as compared with CD44- cells (70). In glioblastoma, it is shown that MDSCs recruited to the tumor microenvironment by CSCs, can promote the survival of CSCs, and also be responsible for the immune-evasive properties. Moreover, the CSCs conditioned media inhibits MDSCs apoptosis and increases arginase 1 (Arg1) production of murine bone marrow derived MDSCs (71). Based on the known evidence and their experimental findings, Gao et al (72) hypothesize that $\mathrm{T}$ cell immunoglobulin mucin-3 (Tim-3), which specifically expresses on Leukemic stem cells (LSCs), is beneficial for LSCs survival and AML progression by promoting expansion of MDSCs and differentiating into tumor-associated macrophages (TAMs) at the leukemia site. In a further study, it is demonstrated that the macrophage migration inhibitory factor (MIF), which was produced at high levels by glioblastoma stem cells, could increase production of the immune-suppressive enzyme Arg1 in MDSCs as a CXCR2-dependent manner (73). In return, MDSCs could enhance the stemness of CSCs in certain ways. In ovarian carcinoma, MDSCs trigger the expression of miRNA101 in cancer cells, which subsequently repressed the corepressor gene $\mathrm{C}$-terminal binding protein-2 (CtBP2), and $\mathrm{CtBP} 2$ directly targets stem cell core genes leading to increased cancer cell stem cells properties and increases metastatic and tumorigenic potential (74). Panni et al (75) revealed that, depending on the activation of the STAT3 pathway, the pancreatic cancer TME transforms monocytes to monocytic MDSCs (Mo-MDSCs), and these cells enhance the stemness and mesenchymal properties CSCs. In a recent study, it is revealed that MDSCs promote tumor initiation by endowing breast cancer cell stemness as well as repressing T-cell activation, and these effects are depended on the crosstalk between STAT3 and NOTCH pathways in cancer cells (76).

As a critical member of the tumor microenvironment, MDSCs lead to not only the tumor-associated immunosuppression, but also the CSCs promotion, and could be a prospective target in anti-tumor treatment, but there are still a lot of efforts needed to put in, such as how to identify MDSCs, the mechanism of MDSCs accumulation in TME, and by which means can suppress MDSCs effectively.

Tumor-associated macrophages (TAMs). TAMs are the macrophages infiltrating in tumor tissue, are the most immune cells in the tumor microenvironment. At first, it is believed that TAMs are able to recognize and eliminate tumor cells by a variety of cytokines, but as the development of research, it is now generally accepted that TAMs play a key role in tumor growth, invasion and migration (77). TAMs derive from monocytic precursors circulating in the vessels, when there is a tumor exists, 
monocytes could be recruited into TME, via the chemokines and cytokines secreted by tumor cells, tumor stromal cells, and immune cells, including chemokine (C-C motif) ligand-2 (CCL2), CCL5, Chemokine (C-X-C motif) ligand-1 (CXCL1), vascular endothelial growth factor (VEGF), platelet derived growth factor (PDGF), TGF and macrophage colony stimulating factor (M-CSF). Affected by the cells and cytokines, mononuclear phagocytes polarize into different types of TAM. Typically activated M1 macrophages are induced by IFN- $\gamma$ alone or in cooperation with microbial stimuli (i.e., LPS) or cytokines (i.e., TNF and GM-CSF). On the other hand, IL-4 and IL-13 induce M2 macrophages alternatively (78). M1 macrophages often show a capability of anti-tumor, such as releasing toxic intermediates and proinflammatory cytokines, inducing specific immune response, and enhancing the antigen presenting. In contrast, M2 macrophages represent as a pro-tumor factor, through suppressing the inflammatory responses, promoting angiogenesis, inducing the invasion and metastasis of tumor. It is accepted that TAMs have functions and phenotype more similar to M2 macrophages, so TAMs are often considered as promoter of tumor progression (79).

A lot of evidences have clarified that TAMs and CSCs have close contact with each other, and the interaction between them play a critical role in tumorigenesis, progression, invasion, drug resistance and so on (80). Jinushi et al (81) found that TAMs produced amount of Milk-fat globule EGF-8 (MFG-E8) in stimulation with lung CSCs. The MFG-E8 enhanced tumorigenicity and drug resistance in CSCs, by means of the coordinated activation of STAT3 and Sonic Hedgehog signals. Furthermore, MFG-E8 and IL-6 from TAMs could synergistically mediate tumorigenesis and drug resistance within CSC. In breast cancer, it is reported that after the cocultivation of M2 macrophages and breast cancer cell lines MCF-7, hybrids can be isolated from the fusion, and they represent a more invasive phenotype, including increased migration, aggression and tumorigenicity, which implicated the role of TAMs in promoting CSCs (82). Additionally, by releasing high levels of TGF- $\beta 1$, TAMs promote the invasion of glioma stem-like cells (GSLCs) and increase the production of MMP-9, then induce EMT (83). The role of TGF- $\beta 1 /$ EMT is also revealed in hepatocellular carcinoma (84). Likewise, the importance of EGFR/Stat3/Sox-2 and IL-6/STAT3 signaling pathway in regulating CSCs also shows up in breast cancer and hepatocellular carcinoma (85-87).

Through the way of interaction, CSCs could recruit TAMs to promote tumor growth. It is demonstrated that the $\mathrm{CD} 34^{-}$ melanoma tumor-initiating cells (TICs) interact specifically with M2 macrophages, then support their resistance to chemotherapeutic drugs and accelerate cancer progression by TGF- $\beta$ and arginase pathway (88). Zhou et al (89) and Shi et al (90) found that in Glioblastoma, the periostin (POSTN) preferentially secreted by GSCs could correlates with TAM density in primary GBMs. Silencing POSTN in GSCs can reduce TAM recruitment, inhibit tumor growth, and extend survival of mice bearing GSC-derived xenografts. Furthermore, they revealed that POSTN recruits TAMs via integrin $\alpha_{v} \beta_{3}$ signaling.

For the significance of the relationship between TAMs and CSCs, the coexpression of them could be a meaningful marker to the tumor diagnosis and prognostic, as well as a promising therapy target $(91,92)$. We propose that the elimination or re-differentiation of macrophages within the tumor microenvironment could be a significant prong of combination therapies designed to treat malignancies.

\section{Conclusion}

Currently, cancer is still one of the biggest threats to human life. Despite of all the efforts have been put in the studies of tumor treatment in recent decades, the survival rate has not apparently been improved. Inflammatory TME mainly show up the promotion of CSCs, but sometimes it also represent as an inhibitory factor to the tumor. The mechanism of the role transformation is still not clear, so furthermore experimental and clinical researches are needed to shed light on the fundamental mechanisms. Given that Inflammatory TME and CSCs are two major barriers to valid cancer therapy, targeting them may provide a promising approach to developing novel treatments.

\section{Acknowledgements}

This study was supported by Research Grants (15411950300) from Science and Technology Commission of Shanghai Municipality, Science and Technology Commission Foundation of Shanghai (no. 10DZ1951300) and Shanghai Summit \& Plateau Disciplines (to CPZ), the National Natural Science Foundation of China (no. 81771046) and Shanghai Summit \& Plateau Disciplines (to LW), Natural Science Foundation of China (no. 81602367 to XY).

\section{References}

1. Bonnet D and Dick JE: Human acute myeloid leukemia is organized as a hierarchy that originates from a primitive hematopoietic cell. Nat Med 3: 730-737, 1997.

2. Albini A, Bruno A, Gallo C, Pajardi G, Noonan DM and Dallaglio K: Cancer stem cells and the tumor microenvironment: Interplay in tumor heterogeneity. Connect Tissue Res 56: 414-425, 2015

3. Voog J and Jones DL: Stem cells and the niche: A dynamic duo. Cell Stem Cell 6: 103-115, 2010.

4. Kise K, Kinugasa-Katayama Y and Takakura N: Tumor microenvironment for cancer stem cells. Adv Drug Deliv Rev 99: 197-205, 2016.

5. Elinav E, Nowarski R, Thaiss CA, Hu B, Jin C and Flavell RA: Inflammation-induced cancer: Crosstalk between tumours, immune cells and microorganisms. Nat Rev Cancer 13: 759-771, 2013.

6. Corrales L and Gajewski TF: Molecular pathways: Targeting the stimulator of interferon genes (STING) in the immunotherapy of cancer. Clin Cancer Res 21: 4774-4779, 2015.

7. Trinchieri G: Type I interferon: Friend or foe? J Exp Med 207: 2053-2063, 2010.

8. Zaidi MR and Merlino G: The two faces of interferon- $\gamma$ in cancer. Clin Cancer Res 17: 6118-6124, 2011.

9. Beyer Nardi N and da Silva Meirelles L: Mesenchymal stem cells: Isolation, in vitro expansion and characterization. Handb Exp Pharmacol: 249-282, 2006.

10. Shi S and Gronthos S: Perivascular niche of postnatal mesenchymal stem cells in human bone marrow and dental pulp. J Bone Miner Res 18: 696-704, 2003.

11. Sharma RR, Pollock K, Hubel A and Mckenna D: Mesenchymal stem or stromal cells: A review of clinical applications and manufacturing practices. Transfusion 54: 1418-1437, 2014.

12. Wang L, Zhao Y, Liu Y, Akiyama K, Chen C, Qu C, Jin Y and Shi S: IFN- $\gamma$ and TNF- $\alpha$ synergistically induce mesenchymal stem cell impairment and tumorigenesis via $\mathrm{NF} \kappa \mathrm{B}$ signaling. Stem Cells 31: 1383-1395, 2013. 
13. Liu Y, Wang L, Kikuiri T, Akiyama K, Chen C, Xu X, Yang R, Chen W, Wang S and Shi S: Mesenchymal stem cell-based tissue regeneration is governed by recipient $\mathrm{T}$ lymphocytes via IFN- $\gamma$ and TNF- $\alpha$. Nat Med 17: 1594-1601, 2011.

14. Trivanović D, Jauković A, Krstić J, Nikolić S, Okić Djordjević I, Kukolj T, Obradović H, Mojsilović S, Ilić V, Santibanez JF and Bugarski D: Inflammatory cytokines prime adipose tissue mesenchymal stem cells to enhance malignancy of MCF-7 breast cancer cells via transforming growth factor- $\beta 1$. IUBMB Life 68: 190-200, 2016.

15. Lv N, Gao Y, Guan H, Wu D, Ding S, Teng W and Shan Z: Inflammatory mediators, tumor necrosis factor- $\alpha$ and interferon- $\gamma$, induce EMT in human PTC cell lines. Oncol Lett 10: 2591-2597, 2015.

16. Schürch $\mathrm{C}$, Riether $\mathrm{C}$, Amrein $\mathrm{MA}$ and Ochsenbein $\mathrm{AF}$ : Cytotoxic $\mathrm{T}$ cells induce proliferation of chronic myeloid leukemia stem cells by secreting interferon- $\gamma$. J Exp Med 210: 605-621, 2013.

17. Zhu Y, Karakhanova S, Huang X, Deng SP, Werner J and Bazhin AV: Influence of interferon- $\alpha$ on the expression of the cancer stem cell markers in pancreatic carcinoma cells. Exp Cell Res 324: 146-156, 2014.

18. Yamashina T, Baghdadi M, Yoneda A, Kinoshita I, Suzu S, Dosakaakita $\mathrm{H}$ and Jinushi $\mathrm{M}$ : Cancer stem-like cells derived from chemoresistant tumors have a unique capacity to prime tumorigenic myeloid cells. Cancer Res 74: 2698-2709, 2014.

19. Jin X, Kim SH, Jeon HM, Beck S, Sohn YW, Yin J, Kim JK, Lim YC, Lee JH, Kim SH, et al: Interferon regulatory factor 7 regulates glioma stem cells via interleukin-6 and Notch signalling. Brain 135: 1055-1069, 2012.

20. Ojha R, Singh SK and Bhattacharyya S: JAK-mediated autophagy regulates stemness and cell survival in cisplatin resistant bladder cancer cells. Biochim Biophys Acta 1860: 2484-2497, 2016.

21. Li J, Chen JN, Zeng TT, He F, Chen SP, Ma S, Bi J, Zhu XF and Guan XY: CD133+ liver cancer stem cells resist interferon-gamma-induced autophagy. BMC Cancer 16: 15 , 2016

22. Furuta J, Inozume T, Harada K and Shimada S: CD271 on melanoma cell is an IFN- $\gamma$-inducible immunosuppressive factor that mediates downregulation of melanoma antigens. J Invest Dermatol 134: 1369-1377, 2014.

23. Kharma B, Baba T, Matsumura N, Kang HS, Hamanishi J, Murakami R, McConechy MM, Leung S, Yamaguchi $\mathrm{K}$, Hosoe Y, et al: STAT1 drives tumor progression in serous papillary endometrial cancer. Cancer Res 74: 6519-6530, 2014.

24. Wang AM, Creasey AA, Ladner MB, Lin LS, Strickler J, Van Arsdell JN, Yamamoto R and Mark DF: Molecular cloning of the complementary DNA for human tumor necrosis factor Science 228: 149-154, 1985

25. Roberts NJ, Zhou S, Diaz LA and Matthias H: Systemic use of tumor necrosis factor alpha as an anticancer agent. Oncotarget 2 : 739-751, 2011.

26. Zhang L, Jiao M, Wu K, Li L, Zhu G, Wang X, He D and Wu D: TNF- $\alpha$ induced epithelial mesenchymal transition increases stemness properties in renal cell carcinoma cells. Int J Clin Exp Med 7: 4951-4958, 2014.

27. Techasen A, Namwat N,Loilome W, Bungkanjana P, Khuntikeo N, Puapairoj A, Jearanaikoon P, Saya H and Yongvanit P: Tumor necrosis factor- $\alpha$ (TNF- $\alpha$ ) stimulates the epithelial-mesenchymal transition regulator Snail in cholangiocarcinoma. Med Oncol 29: 3083-3091, 2012

28. Valizadeh A, Ahmadzadeh A, Saki G, Khodadadi A and Teimoori A: Role of tumor necrosis factor-producing mesenchymal stem cells on apoptosis of chronic B-lymphocytic tumor cells resistant to fludarabine-based chemotherapy. Asian Pac J Cancer Prev 16: 8533-8539, 2015.

29. Yu PF, Huang Y, Han YY, Lin LY, Sun WH, Rabson AB, Wang Y and Shi YF: TNF $\alpha$-activated mesenchymal stromal cells promote breast cancer metastasis by recruiting CXCR2+ neutrophils. Oncogene 36: 482-490, 2017.

30. Katanov C, Lerrer S, Liubomirski Y, Leider-Trejo L, Meshel T, Bar J, Feniger-Barish R, Kamer I, Soria-Artzi G, Kahani H, et al: Regulation of the inflammatory profile of stromal cells in human breast cancer: Prominent roles for TNF- $\alpha$ and the NF- $\mathrm{BB}$ pathway. Stem Cell Res Ther 6: 87, 2015.

31. Lee SH, Hong HS, Liu ZX, Kim RH, Kang MK, Park NH and Shin KH: TNFa enhances cancer stem cell-like phenotype via Notch-Hes1 activation in oral squamous cell carcinoma cells. Biochem Biophys Res Commun 424: 58-64, 2012.
32. Storci G, Sansone P, Mari S, D'Uva G, Tavolari S, Guarnieri T, Taffurelli M, Ceccarelli C, Santini D, Chieco P, et al: TNFalpha up-regulates SLUG via the NF-kappaB/HIFlalpha axis, which imparts breast cancer cells with a stem cell-like phenotype. J Cell Physiol 225: 682-691, 2010.

33. Ostyn P, El Machhour R, Begard S, Kotecki N, Vandomme J, Flamenco P, Segard P, Masselot B, Formstecher P, Touil Y and Polakowska R: Transient TNF regulates the self-renewing capacity of stem-like label-retaining cells in sphere and skin equivalent models of melanoma. Cell Commun Signal 12: 52, 2014.

34. Fukushima K, Tsuchiya K, Kano Y, Horita N, Hibiya S, Hayashi R, Kitagaki K, Negi M, Itoh E, Akashi T, et al: Atonal homolog 1 protein stabilized by tumor necrosis factor $\alpha$ induces high malignant potential in colon cancer cell line. Cancer Sci 106: 1000-1007, 2015

35. Gallipoli P, Pellicano F, Morrison H, Laidlaw K, Allan EK, Bhatia R, Copland M, Jørgensen HG and Holyoake TL: Autocrine TNF- $\alpha$ production supports CML stem and progenitor cell survival and enhances their proliferation. Blood 122: 3335-3339, 2013.

36. Zhou X, Zhou S, Li B, Li Q, Gao L, Li D, Gong Q, Zhu L, Wang J, Wang N, et al: Transmembrane TNF- $\alpha$ preferentially expressed by leukemia stem cells and blasts is a potent target for antibody therapy. Blood 126: 1433-1442, 2015

37. Sheng YH, He Y, Hasnain SZ, Wang R, Tong H, Clarke DT, Lourie R, Oancea I, Wong KY,Lumley JW, et al: MUC13 protects colorectal cancer cells from death by activating the NF- $\mathrm{KB}$ pathway and is a potential therapeutic target. Oncogene 36: 700-713, 2017.

38. Nenu I, Tudor D, Filip AG and Baldea I: Current position of TNF- $\alpha$ in melanomagenesis. Tumor Biol 36: 6589-6602, 2015.

39. Bromberg J and Wang TC: Inflammation and cancer: IL-6 and STAT3 complete the link. Cancer Cell 15: 79-80, 2009.

40. Smith PC, Hobisch A, Lin DL, Culig Z and Keller ET: Interleukin- 6 and prostate cancer progression. Cytokine Growth Factor Rev 12: 33-40, 2001

41. Yao X, Huang J, Zhong H, Shen N, Faggioni R, Fung M and Yao Y: Targeting interleukin-6 in inflammatory autoimmune diseases and cancers. Pharmacol Ther 141: 125-139, 2014.

42. Hideshima T, Nakamura N, Chauhan D and Anderson KC: Biologic sequelae of interleukin-6 induced PI3-K/Akt signaling in multiple myeloma. Oncogene 20: 5991-6000, 2001.

43. Kumari N, Dwarakanath BS, Das A and Bhatt AN: Role of interleukin-6 in cancer progression and therapeutic resistance. Tumor Biol 37: 11553-11572, 2016.

44. Chen Y, Zhang F, Tsai Y, Yang X, Yang L, Duan S, Wang X, Keng $P$ and Lee SO: IL-6 signaling promotes DNA repair and prevents apoptosis in CD133+ stem-like cells of lung cancer after radiation. Radiat Oncol 10: 227, 2015.

45. Altundag O, Altundag K and Gunduz E: Interleukin- 6 and C-reactive protein in metastatic renal cell carcinoma. J Clin Oncol 23: 1044-1045, 2005 .

46. Knüpfer H and Preiß R: Significance of interleukin-6 (IL-6) in breast cancer (review). Breast Cancer Res Treat 102: 129-135, 2007.

47. Ok LS, Yang X, Duan S, Ying T, Strojny LR, Peter K, et al: IL-6 promotes growth and epithelial-mesenchymal transition of CD133+ cells of non-small cell lung cancer. Oncotarget 7: 6626-6638, 2016

48. Zhang F, Duan S, Ying T, Keng PC, Chen Y, Lee SO and Chen Y: Cisplatin treatment increases stemness through upregulation of hypoxia-inducible factors by interleukin- 6 in non-small cell lung cancer. Cancer Sci 107: 746-754, 2016.

49. Liu CC, Lin JH, Hsu TW, Su K, Li AF, Hsu HS and Hung SC: IL-6 enriched lung cancer stem-like cell population by inhibition of cell cycle regulators via DNMT1 upregulation. Int J Cancer 136: 547-559, 2015.

50. Hsu HS, Lin JH, Hsu TW, Su K, Wang CW, Yang KY, Chiou SH and Hung SC: Mesenchymal stem cells enhance lung cancer initiation through activation of IL-6/JAK2/STAT3 pathway. Lung Cancer 75: 167-177, 2012.

51. Lu JH, Wei HJ, Peng BY, Chou HH, Chen WH, Liu HY and Deng WP: Adipose-derived stem cells enhance cancer stem cell property and tumor formation capacity in lewis lung carcinoma cells through an interleukin-6 paracrine circuit. Stem Cells Dev 25: 1833-1842, 2016.

52. a Dzaye OD, Hu F, Derkow K, Haage V, Euskirchen P, Harms C, Lehnardt S, Synowitz M, Wolf SA and Kettenmann H: Glioma stem cells but not bulk glioma cells upregulate IL-6 secretion in microglia/brain macrophages via toll-like receptor 4 signaling. J Neuropathol Exp Neurol 75: 429-440, 2016. 
53. Ding DC, Liu HW and Chu TY: Interleukin-6 from ovarian mesenchymal stem cells promotes proliferation, sphere and colony formation and tumorigenesis of an ovarian cancer cell line SKOV3. J Cancer 7: 1815-1823, 2016.

54. Huynh PT, Beswick EJ, Yun AC, Johnson P, O'Connell MR, Watts T, Singh P, Qiu S, Morris K, Powell DW and Pinchuk IV: CD90(+) stromal cells are the major source of IL-6, which supports cancer stem-like cells and inflammation in colorectal cancer. Int J Cancer 138: 1971-1981, 2016.

55. Wang X, Sun W, Shen W, Xia M, Chen C, Xiang D, Ning B, Cui X, Li H, Li X, et al: Long non-coding RNA DILC regulates liver cancer stem cells via IL-6/STAT3 axis. J Hepatol 64 1283-1294, 2016.

56. Mcnee G, Eales KL, Wei W, Williams DS, Barkhuizen A, Bartlett DB, Essex S, Anandram S, Filer A, Moss PA, et al: Citrullination of histone $\mathrm{H} 3$ drives IL- 6 production by bone marrow mesenchymal stem cells in MGUS and multiple myeloma. Leukemia 31: 373-381, 2017.

57. Kolls JK and Lindén A: Interleukin-17 family members and inflammation. Immunity 21: 467-476, 2004.

58. Guéry L and Hugues S: Th17 cell plasticity and functions in cancer immunity. Biomed Res Int 2015: 314620, 2015.

59. Yang B, Fung A, Zhao H, Wang T and Ma D: The Role of Interleukin 17 in Tumour Proliferation, Angiogenesis and Metastasis. Mediators of Inflammation 2014: 390-392, 2014.

60. Yang S, Wang B, Guan C, Wu B, Cai C, Wang M, Zhang B, Liu T and Yang P: Foxp3+IL-17+ T cells promote development of cancer-initiating cells in colorectal cancer. J Leukoc Biol 89: 85-91, 2011.

61. Wei S,Zhao E, Kryczek I andZou W: Th17 cells have stem cell-like features and promote long-term immunity. Oncoimmunology 1 : 516-519, 2012

62. Lotti F, Jarrar AM, Pai RK, Hitomi M, Lathia J, Mace A Gantt GA Jr, Sukhdeo K, DeVecchio J, Vasanji A, et al: Chemotherapy activates cancer-associated fibroblasts to maintain colorectal cancer-initiating cells by IL-17A. J Exp Med 210: $2851-2872,2013$

63. Xiang T, Long H, He L, Han X, Lin K, Liang Z, Zhuo W, Xie R and Zhu B: Interleukin-17 produced by tumor microenvironment promotes self-renewal of CD133+ cancer stem-like cells in ovarian cancer. Oncogene 34: 165-176, 2015.

64. Luo Y, Yang Z, Su L, Shan J, Xu H, Xu Y, Liu L, Zhu W, Chen X, Liu C, et al: Non-CSCs nourish CSCs through interleukin-17E-mediated activation of NF- $\mathrm{BB}$ and JAK/STAT3 signaling in human hepatocellular carcinoma. Cancer Lett 375: 390-399, 2016.

65. Parajuli P, Anand R, Mandalaparty C, Suryadevara R, Sriranga PU, Michelhaugh SK, Cazacu S, Finniss S, Thakur A, Lum LG, et al: Preferential expression of functional IL-17R in glioma stem cells: Potential role in self-renewal. Oncotarget 7: 6121-6135, 2016

66. Jiang YX, Yang SW, Li PA, Luo X, Li ZY, Hao YX and Yu PW: The promotion of the transformation of quiescent gastric cancer stem cells by IL-17 and the underlying mechanisms. Oncogene 36: 1256-1264, 2017.

67. Gabrilovich DI and Nagaraj S: Myeloid-derived suppressor cells as regulators of the immune system. Nat Rev Immunol 9: $162-174,2009$

68. Condamine T and Gabrilovich DI: Molecular mechanisms regulating myeloid-derived suppressor cell differentiation and function. Trends Immunol 32: 19-25, 2011.

69. Medina-Echeverz J, Aranda F and Berraondo $P$. Myeloid-derived cells are key targets of tumor immunotherapy. Oncoimmunology 3: e28398, 2014.

70. Chikamatsu K, Okamoto A, Sakakura K, Hatsushika K, Takahashi G and Masuyama K: P3.14. Immunoregulatory properties of CD44+ cancer stem-like cells in squamous cell carcinoma of the head and neck. Oral Oncol Suppl 3: 205-206, 2009.

71. Otvos B, Finke J, Vogelbaum M and Lathia JD: Interrogating the interactions between myeloid derived suppressor cells and cance stem cells in glioblastoma. J Immuno Ther Cancer 1: 268, 2013.

72. Gao L, Yu S and Zhang X: Hypothesis: Tim-3/galectin-9, a new pathway for leukemia stem cells survival by promoting expansion of myeloid-derived suppressor cells and differentiating into tumor-associated macrophages. Cell Biochem Biophys 70 273-277, 2014

73. Otvos B, Silver DJ, Mulkearns-Hubert EE, Alvarado AG, Turaga SM, Sorensen MD, Rayman P, Flavahan WA, Hale JS Stoltz K, et al: Cancer stem cell-secreted macrophage migration inhibitory factor stimulates myeloid derived suppressor cell function and facilitates glioblastoma immune evasion. Stem Cells 34: 2026-2039, 2016.
74. Cui TX, Kryczek I, Zhao L, Zhao E, Kuick R, Roh MH, Vatan L, Szeliga W, Mao Y, Thomas DG, et al: Myeloid-derived suppressor cells enhance stemness of cancer cells by inducing microRNA101 and suppressing the corepressor CtBP2. Immunity 39: 611-621, 2013.

75. Panni RZ, Sanford DE, Belt BA, Mitchem JB, Worley LA, Goetz BD, Mukherjee P, Wang-Gillam A, Link DC, Denardo DG, et al: Tumor-induced STAT3 activation in monocytic myeloid-derived suppressor cells enhances stemness and mesenchymal properties in human pancreatic cancer. Cancer Immunol Immunother 63: 513-528, 2014.

76. Peng D, Tanikawa T, Li W, Zhao L, Vatan L, Szeliga W, Wan S, Wei S, Wang Y, Liu Y, et al: Myeloid-derived suppressor cells endow stem-like qualities to breast cancer cells through IL6/STAT3 and NO/NOTCH cross-talk signaling. Cancer Res 76: 3156-3165, 2016.

77. Shih JY, Yuan A, Chen JW and Yang PC: Tumor-associated macrophage: Its role in cancer invasion and metastasis. J Cancer Mol 2: 101-106, 2006.

78. Allavena P, Sica A, Solinas G, Porta C and Mantovani A: The inflammatory micro-environment in tumor progression: The role of tumor-associated macrophages. Crit Rev Oncol Hematol 66: $1-9,2008$

79. Franklin RA, Liao W, Sarkar A, Kim MV, Bivona MR, Liu K, Pamer EG and Li MO: The cellular and molecular origin of tumor-associated macrophages. Science 344: 921-925, 2014.

80. Raggi C, Mousa HS, Correnti M, Sica A and Invernizzi P: Cancer stem cells and tumor-associated macrophages: A roadmap for multitargeting strategies. Oncogene 35: 671-682, 2016.

81. Jinushi M, Chiba S, Yoshiyama H, Masutomi K, Kinoshita I, Dosaka-Akita H, Yagita H, Takaoka A and Tahara H: Tumor-associated macrophages regulate tumorigenicity and anticancer drug responses of cancer stem/initiating cells. Proc Natl Acad Sci USA 108: 12425-12430, 2011.

82. Ding J, Jin W, Chen C, Shao Z and Wu J: Tumor associated macrophage $\times$ cancer cell hybrids may acquire cancer stem cell properties in breast cancer. PLoS One 7: e41942, 2012.

83. YeXZ,Xu SL, Xin YH, Yu SC, Ping YF, Chen L, Xiao HL, Wang B, Yi L, Wang QL, et al: Tumor-associated microglia/macrophages enhance the invasion of glioma stem-like cells via TGF- $\beta 1$ signaling pathway. J Immunol 189: 444-453, 2012.

84. Fan QM, Jing YY, Yu GF, Kou XR, Ye F, Gao L, Li R, Zhao QD, Yang Y, Lu ZH and Wei LX: Tumor-associated macrophages promote cancer stem cell-like properties via transforming growth factor-beta1-induced epithelial-mesenchymal transition in hepatocellular carcinoma. Cancer Lett 352: 160-168, 2014.

85. Yang J, Liao D, Chen C, Liu Y, Chuang TH, Xiang R, Markowitz D, Reisfeld RA and Luo Y: Tumor-associated macrophages regulate murine breast cancer stem cells through a novel paracrine EGFR/Stat3/Sox-2 signaling pathway. Stem Cells 31: 248-258, 2013.

86. Zhou N, Zhang Y, Zhang X, Lei Z, Hu R, Li H, Mao Y, Wang X, Irwin DM, Niu G and Tan H: Exposure of tumor-associated macrophages to apoptotic MCF-7 cells promotes breast cancer growth and metastasis. Int J Mol Sci 16: 11966-11982, 2015.

87. Wan S, Zhao E, Kryczek I, Vatan L, Sadovskaya A, Ludema G, Simeone DM, Zou W and Welling TH: Tumor-associated macrophages produce interleukin 6 and signal via STAT3 to promote expansion of human hepatocellular carcinoma stem cells. Gastroenterology 147: 1393-1404, 2014.

88. Tham M, Tan KW, Keeble J, Wang X, Hubert S, Barron L, Tan NS, Kato M, Prevost-Blondel A, Angeli V and Abastado JP: Melanoma-initiating cells exploit M2 macrophage TGF $\beta$ and arginase pathway for survival and proliferation. Oncotarget 5 : 12027-12042, 2014.

89. Zhou W, Ke SQ, Huang Z, Flavahan W, Fang X, Paul J, Wu L, Sloan AE, McLendon RE, Li X, et al: Periostin secreted by glioblastoma stem cells recruits M2 tumour-associated macrophages and promotes malignant growth. Nat Cell Biol 17: 170-182, 2015.

90. Shi Y, Ping Y, Zhang X and Bian XW: Hostile takeover: Glioma stem cells recruit TAMs to support tumor progression. Cell Stem Cell 16: 219-220, 2015.

91. He KF, Zhang L, Huang CF, Ma SR, Wang YF, Wang WM, Zhao ZL, Liu B, Zhao YF, Zhang WF and Sun ZJ: CD163+ tumor-associated macrophages correlated with poor prognosis and cancer stem cells in oral squamous cell carcinoma. Biomed Res Int 2014: 838632, 2014

92. Hou YC, Chao YJ, Tung HL, Wang HC and Shan YS: Coexpression of CD44-positive/CD133-positive cancer stem cells and CD204-positive tumor-associated macrophages is a predictor of survival in pancreatic ductal adenocarcinoma. Cancer 120: 2766-2777, 2014 